\title{
FUNCTIONAL TRICUSPID INCOMPETENCE IN RELATION TO THE VENOUS PRESSURE
}

\author{
BY \\ CONRAD LOTTENBACH AND JOHN SHILLINGFORD* \\ From the Department of Medicine, Postgraduate Medical School, Hammersmith, London
}

Received October 23, 1956

Observations on the right atrial pulse (Korner and Shillingford, 1954), right atrial blood flow (Müller and Shillingford, 1955), and dye circulation studies (Korner and Shillingford, 1955) have confirmed the clinical impression (Müller and Shillingford, 1954) that functional tricuspid incompetence is common in congestive cardiac failure where the venous pressure is raised to a mean level of $8 \mathrm{~mm}$. of mercury above the normal average zero. Further observations on the tricuspid valve at necropsy have added confirmation to these findings and the purpose of this paper is to show that there is a relationship between the presence of an incompetent valve at necropsy and a grossly raised venous pressure during life, and to study the mechanism involved in the production of this incompetence.

\section{Historical Note}

In 1835, King placed in the museum of Guy's Hospital more than 300 specimens to illustrate the anatomy and function of the tricuspid valve. He published in 1837 a remarkable account of the tricuspid valve and suggested on anatomical grounds that it was responsible for regulating the right ventricular output by becoming incompetent if the right ventricle became dilated; this, in turn, would prevent overfilling of the pulmonary circulation.

His description of the valve is as follows, "The right atrioventricular opening is oval and to its circumference the membrane of the tricuspid valve has attachment without any distinct interruptions whilst its floating border, depending into the ventricle, is deeply fissured, so as to form three or more scalloped or angular curtains; and it appears, from careful examination, that the united areas of these valvular portions are scarcely more than equal to the mean extent of the oval opening. One of the curtains (which being least moveable, I have called fixed) occupies the left margin of the aperture in apposition with the solid wall from which arise all the cords that serve to secure the free edge and the ventricular surface of the fixed curtain. These cords are of such a length as scarcely to allow the curtain to rise into the plane of the oval opening in the natural play of the valve, and being destitute of muscular columns cannot, by any possibility, set the valve in motion or serve any other purpose than that of preventing too great a reflux of the curtain itself. A second curtain (the anterior) is attached at the anterior and right edge of the opening, having one free border and another backwards in the ventricle. Each border has its proper set of cords, the anterior or upper set have their insertion into a mere nipple of muscle on the solid wall, in the direction of the pulmonary artery; and the inferior or posterior are as invariably collected with numerous others into the summit of a muscular column whose base is inserted into the right or yielding wall of the ventricle near its centre ... is frequently fissured. . . Its cords are accordingly arranged in two or more sets, the greater part of which are attached by the intervention of muscular columns to the outer yielding wall at a considerable distance." (Then he goes on to describe it in great detail.)

\section{Methods AND Materials}

The hearts from 25 subjects were examined at necropsy in the routine way. Fifteen were from patients in whom there was no evidence of cardiac disease in life or at subsequent necropsy. Ten cases had evidence of congestive cardiac failure with a raised venous pressure in life and included chronic rheumatic (3), ischæmic (1), hypertensive (2), pulmonary (3), and anæmic (1) heart disease.

In addition a rubber tube was inserted through the intact pulmonary artery into the right ventricle. Water was allowed to flow gently through this and distend the right ventricle while the 
whole heart was held in the hand under water. The behaviour of the tricuspid valve could then be watched through the opened right atrium. An incompetent orifice was measured and in addition photographs were taken by electronic flash in all cases. Although in the earlier cases an attempt was made to standardize the perfusion pressure it was found that this made photography impossible in some, due to the rapid regurgitant stream obscuring the field. In practice, gentle perfusion in no case gave more than the slightest incompetence in control hearts, whereas those who had congestive failure in life showed varying degrees of incompetence. Rigor mortis also affected the behaviour of the right ventricle and a high degree of physical accuracy is of course not possible in this test, but the results were clear cut in the majority of cases even allowing for the experimental error.

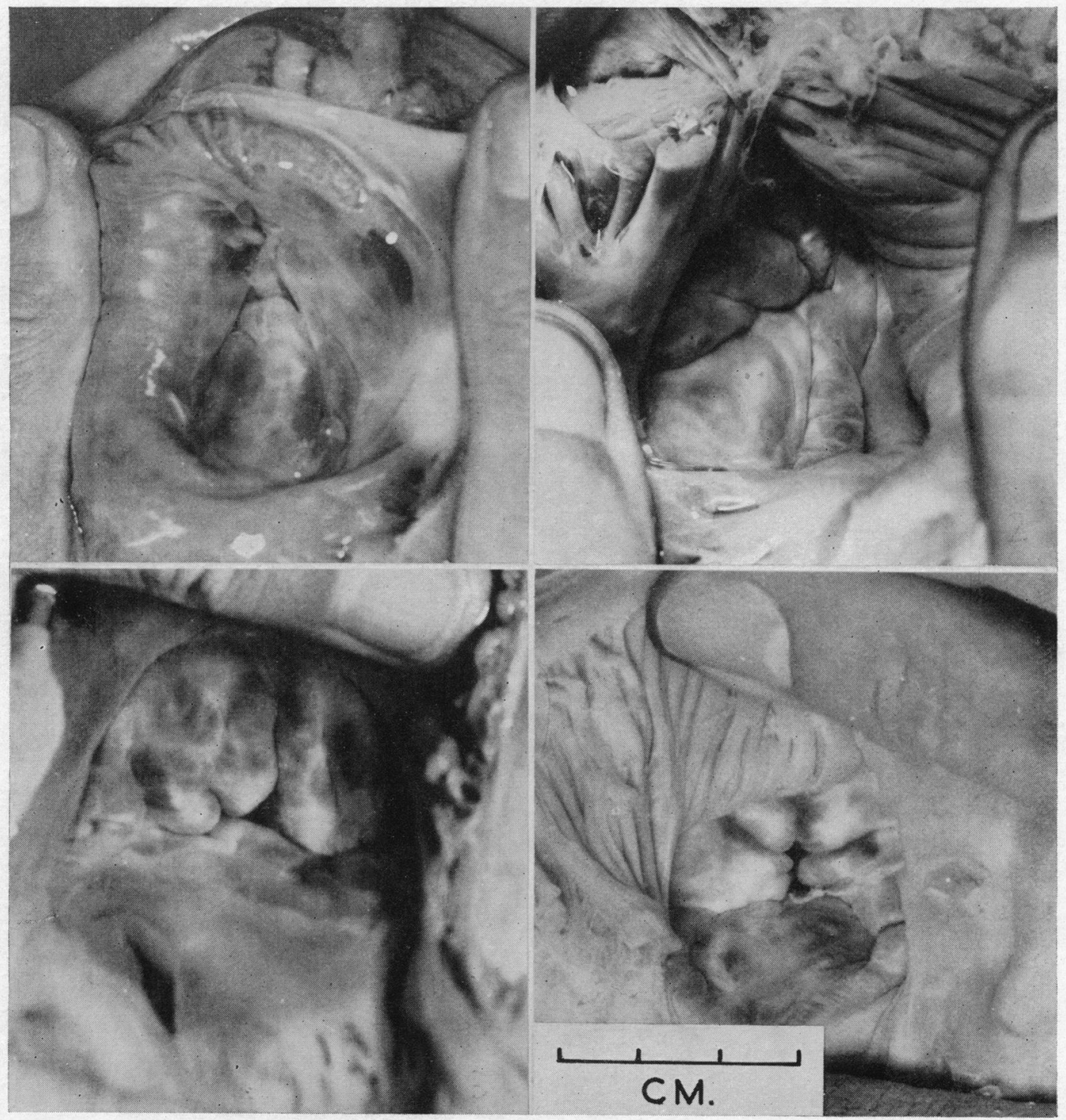

Fig. 1.-The perfused tricuspid valve photographed under water through the opened left atrium in four subjects without evidence of cardiac disease. The lower two show the maximum aperture of reflux found in the normal group. 


\section{RESULTS}

The fifteen hearts from subjects who had no heart disease in life all showed a competent tricuspid valve (Fig. 1); the three leaflets approximated along their free edges with no orifice at their centre. Increasing the pressure in the right ventricle caused a bulging of the cusps, and inversion of the edges at the point where the chordæ were inserted until, if the pressure were enough to dilate the ventricle considerably the valve would leak. Without dilatation of the ventricle, however, the normal valve appears to be watertight.

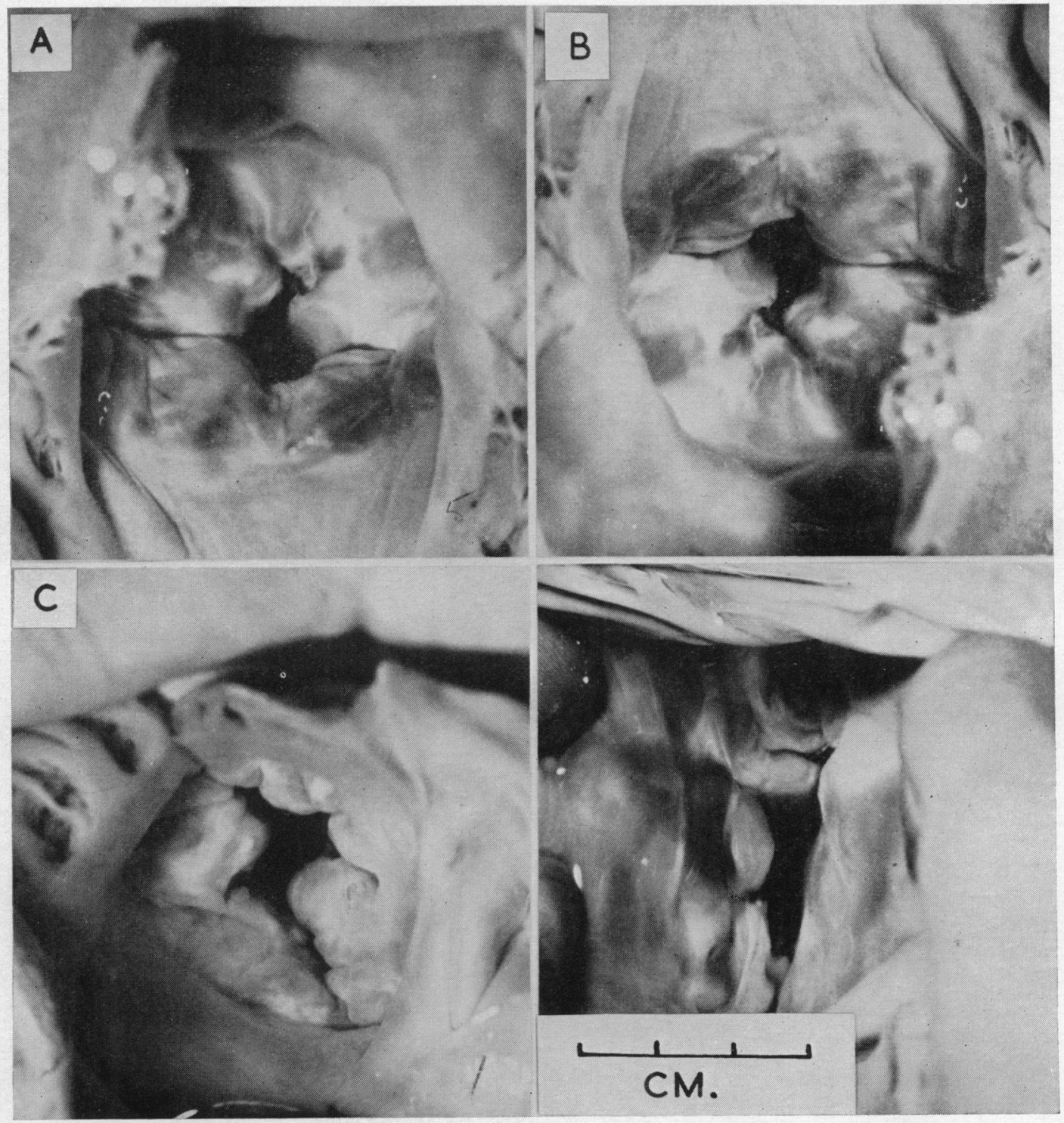

Fig. 2.-The perfused tricuspid valve photographed under water through the opened left atrium in four subjects all of whom in life had evidence of congestive cardiac failure and a raised venous pressure. (A) Ischæmic heart disease, terminal congestive failure with a grossly raised venous pressure. (B) Hypertensive cardiac failure with jugular venous mean pressure of $8 \mathrm{~mm}$. Hg. (C) Severe anæmia secondary to myosclerosis with dilated heart and mean jugular venous pressure over $10 \mathrm{~mm}$. Hg. (D) Chronic rheumatic heart disease and congestive cardiac failure with the mean jugular venous pressure over $10 \mathrm{~mm}$. $\mathrm{Hg}$. 
In the cases in which, in life, there had been congestive cardiac failure, varying amounts of tricuspid incompetence were found by this test. The incompetence appeared to be produced by two different mechanisms, the first by a general dilatation of the right ventricle which pulled the chordæ attached to the edge of the valve in a downward and outward direction. This gave a funnel appearance to the valve (Fig. 2B); the second appeared to be a general dilatation of the valve ring. The size of the orifice varied from a few $\mathrm{mm}$. in diameter up to 8 square $\mathrm{cm}$., the latter being of greater area than the outflow tract of the pulmonary valve.

\section{Discussion}

Both King (1837) on anatomical grounds and Mackenzie (1904) on clinical observation emphasized the frequent occurrence of tricuspid incompetence in congestive heart failure. Recent work of our own has shown regurgitation to occur through the tricuspid valve in association with a rise in the mean right atrial pressure above the level of approximately $8 \mathrm{~mm}$. of mercury. Although the technique employed for measuring the valve orifice at necropsy was the best that we could devise, there are obvious sources of error in assuming that these measurements applied in life. In spite of this the findings of valvular incompetence correlated with the clinical findings of a grossly raised venous pressure and congestive cardiac failure in life. The size of the tricuspid incompetent orifice in severe cases was as large as, or larger than, the outflow tract of the right ventricle and it is therefore apparent that the amount of regurgitant flow in these cases may equal or exceed the forward output of the right ventricle.

The mechanism of the production of incompetence is almost certainly due to dilatation of the right ventricle pulling down the chordæ in the first instance with dilatation of the valve ring developing later. Both mechanisms play a part in the long standing case. Increased filling of the right ventricle with greater dilating will produce a greater degree of incompetence; this is well seen in patients with functional tricuspid incompetence where increasing venous return by exercise or hepatic compression increases the size of the positive systolic wave in the jugular venous pulse. Decreasing the venous return to the ventricle allows the valve cusps to approximate more closely and reduce the regurgitant flow (Korner and Shillingford, 1957).

\section{SUMMARY}

The tricuspid valve has been studied at necropsy in 25 subjects, 10 of whom had congestive cardiac failure in life.

In all cases of congestive cardiac failure in which the mean venous pressure in life was raised above $8 \mathrm{~mm}$. of mercury evidence of tricuspid valvular incompetence was found at necropsy.

The mode of production of this incompetence and its significance is discussed.

We should like to thank Professor McMichael for his continued help and advice.

\section{REFERENCES}

King, T. W. (1837). Guy's Hosp. Rep., 2, 104.

Korner, P., and Shillingford, J. (1954). Brit. Heart J., 16, 447.

- , (1955). Clin. Sci., 14, 553.

- - , (1957). Brit. Heart J., 19, 1.

Mackenzie, J. (1908). Diseases of the Heart. Oxford University Press, London.

Müller, O., and Shillingford, J. (1954). Brit. Heart J., 16, 195.

$\longrightarrow$, , (1955). Brit. Heart J., 17, 163. 